\title{
A Short History of Biosemiotics
}

\section{Marcello Barbieri}

Received: 20 March 2009 /Accepted: 14 April 2009 /

Published online: 6 May 2009

(C) Springer Science + Business Media B.V. 2009

\begin{abstract}
Biosemiotics is the synthesis of biology and semiotics, and its main purpose is to show that semiosis is a fundamental component of life, i.e., that signs and meaning exist in all living systems. This idea started circulating in the 1960s and was proposed independently from enquires taking place at both ends of the Scala Naturae. At the molecular end it was expressed by Howard Pattee's analysis of the genetic code, whereas at the human end it took the form of Thomas Sebeok's investigation into the biological roots of culture. Other proposals appeared in the years that followed and gave origin to different theoretical frameworks, or different schools, of biosemiotics. They are: (1) the physical biosemiotics of Howard Pattee and its extension in Darwinian biosemiotics by Howard Pattee and by Terrence Deacon, (2) the zoosemiotics proposed by Thomas Sebeok and its extension in sign biosemiotics developed by Thomas Sebeok and by Jesper Hoffmeyer, (3) the code biosemiotics of Marcello Barbieri and (4) the hermeneutic biosemiotics of Anton Markoš. The differences that exist between the schools are a consequence of their different models of semiosis, but that is only the tip of the iceberg. In reality they go much deeper and concern the very nature of the new discipline. Is biosemiotics only a new way of looking at the known facts of biology or does it predict new facts? Does biosemiotics consist of testable hypotheses? Does it add anything to the history of life and to our understanding of evolution? These are the major issues of the young discipline, and the purpose of the present paper is to illustrate them by describing the origin and the historical development of its main schools.
\end{abstract}

Keywords Biosemiotics $\cdot$ Signs $\cdot$ Meaning $\cdot$ Codes $\cdot$ Interpretation $\cdot$ Semiosis

M. Barbieri $(\square)$

Dipartimento di Morfologia ed Embriologia, Via Fossato di Mortara 64, 44121 Ferrara, Italy

e-mail: brr@unife.it 


\section{Introduction}

Codes and conventions are the basis of our social life and from time immemorial have divided the world of culture from the world of nature. The rules of grammar, the laws of government, the precepts of religion, the value of money, cooking recipes, fairy tales and the rules of chess are all human conventions that are profoundly different from the laws of physics and chemistry, and this has led to the conclusion that there is an unbridgeable gap between nature and culture. Nature is governed by objective immutable laws, whereas culture is produced by the mutable conventions of the human mind.

In this centuries-old framework, the discovery of the genetic code, in the early 1960s, came as a bolt from the blue, but strangely enough it did not bring down the barrier between nature and culture. On the contrary, a 'protective belt' was quickly built around the old divide with two arguments that effectively emptied the discovery of the code of all its revolutionary potential. One argument is that the genetic code is a metaphor because it must be reducible, in principle, to physical quantities. The other is that it is the only code that exists in nature, whereas countless different codes exist in culture. This amounts to saying that the real world of codes is culture, not nature, and in this case the genetic code can be regarded as a totally isolated accident that somehow appeared at the origin of life.

A few scientists, however, took a completely different approach. Howard Pattee pointed out, in the 1960s, that the discovery of the genetic code means that the cell is a physical system controlled by 'symbols', and underlined that this reveals a totally unexpected aspect of nature. At about the same time, Thomas Sebeok started questioning another of our traditional beliefs, the conviction that semiosis exists only in culture, i.e., that only man makes use of signs. Culture must have biological roots, he argued, so there must be some forms of semiosis in the animal world.

The idea of a union between biology and semiotics — what today we call biosemiotics - started in this way, in the 1960s, with two independent enquiries, one on the genetic code and the other on animal semiosis, and it has grown ever since. The present paper is dedicated to a short history of the new field, and to this purpose is divided into two Parts. The first describes the main schools of biosemiotics, whereas the second illustrates their present differences and the conditions for a unified science.

\section{PART 1 - The Schools of Biosemiotics}

\section{A Molecular Language}

The discovery of the genetic code took place between 1961 and 1966 (Nirenberg and Matthaei 1961; Speyer et al. 1963; Nirenberg et al. 1966; Khorana et al. 1966), and immediately inspired the idea of a deep parallel between the genetic code and the codes of language. This idea was expressed in no uncertain terms by George and Muriel Beadle in 1966: "the deciphering of the genetic code has revealed our possession of a language much older than hieroglyphics, a language as old as life itself, a language that is the most living language of all - even if its letters are 
invisible and its words are buried in the cells of our bodies" (Beadle and Beadle 1966). But was this only a poetic metaphor or can we really say that the genetic code is a true molecular language?

A language is based on signs and can exist only in systems that make use of signs, i.e., in semiotic systems. The genetic code would be therefore a real molecular language only if the cell is a real semiotic system, i.e., only if signs, or symbols, exist inside the cell and are instrumental to its functions. This is the great potential implication of the discovery of genetic code, but can we prove it?

The idea that the cell is controlled by symbols was proposed explicitly for the first time by Howard Pattee at the symposia on theoretical biology organized by Conrad Waddington between 1966 and 1970, and was published in the proceedings of those symposia (Pattee 1968, 1972). The experimental evidence of the genetic code did not seem enough, on its own, to categorize the cell as a semiotic system, but Pattee argued that it becomes enough when we combine it with the theory of self-replicating automata developed by John von Neumann between 1948 and 1951 (von Neumann 1951, 1966).

Von Neumann showed that a self-replicating system capable of open-ended evolution must necessarily contain a description of itself, and such a description must be categorically different from the construction it controls. Self-replication is a two-step process: the first consists in transferring the description to the descendants, and the second in using it to reconstitute the original system in each descendant. The description of a system, on the other hand, cannot coincide with the system itself ("the map is not the territory") so it is necessarily a set of entities that represent, or 'stand for', the material components, and therefore function as symbols. According to von Neumann, in short, an evolvable self-replicating system must be a physical system controlled by symbols.

The discovery that genes carry the information for the synthesis of proteins demonstrated that the cell is a system that contains two distinct categories, a software and a hardware (a genotype and a phenotype). But the cell is also a self-replicating system and Pattee concluded, on the basis of von Neumann's logic, that the genotype must be a symbolic description of the cell. This is the argument that he used to conclude that "life is matter controlled by symbols", a theme that he developed for nearly forty years in various publications (Pattee 1968, 1972, 1973, 1980, 1995, 2001, 2007, 2008). The idea that symbols exist at the cellular level was the first explicit argument in favour of biological semiosis. It was the beginning of what later would become known as biosemiotics.

\section{Physical Biosemiotics}

A substantial contribution to the birth of molecular biology came, in the 1940s and 50 s, from physicists who had been seduced by the idea that the study of life would disclose 'new laws of physics', a prophecy that had been made by some of the founding fathers of quantum theory like Niels Bohr (1933) and Erwin Schrödinger (1944). By the 1960s, however, any interest in new laws of physics had virtually disappeared, and most biologists were accepting that life is completely accounted for by the known principles of physics and chemistry.

The result is that modern biology accepted the concept of information but not the concept of meaning, because meaning does not belong to physical theory. But 
meaning is inseparable from semiosis, so how can we explain the existence of symbols and codes in the cell by relying only on known physical principles?

This is the problem that Pattee set out to resolve, and his starting point was the idea that physical theory does not consists only of physical laws. Influenced by Michael Polanyi, he saw that it consists of laws plus initial conditions and boundary conditions that are often referred to as constraints. This had been known since Newton's time, but physicists had consistently assumed that laws are fundamental whereas constraints have only an accessory role. The reality, however, turned out to be very different. Murray Gell-Mann (1994) has underlined that "the effective complexity of the universe receives only a small contribution from the fundamental laws. The rest comes from 'frozen accidents', which are precisely the result of constraints". All planets, for example, are formed according to universal physical laws, and yet they are all different. Their individual features are due to the particular constraints of their development, and the distinction between laws and constraints is so important that Wigner (1964) called it "Newton's greatest discovery".

In this novel theoretical framework, where laws and constraints have equally fundamental roles, Pattee explained that symbols and codes are perfectly compatible with normal physical theory because they have precisely the defining features of constraints. The rules of a code, for example, are limitations that drastically reduce the number of possibilities and can be regarded therefore as true natural constraints. In a similar way, Claude Shannon underlined that information is obtained whenever uncertainty is reduced, and concluded from this that the notions of information and constraint are interchangeable (Shannon 1948).

The solution proposed by Pattee, in short, is that signs and codes do not require new laws of physics, because they are a special type of constraints and constraints are an integral part of normal physical theory. The whole argument is developed in three logical steps: (1) life requires evolvable self-replication (a biological principle), (2) evolvability requires symbolic control of self-replication (von Neumann), and (3) physics requires that symbols and codes are special types of constraints (Pattee).

This proposal is undoubtedly a form of biosemiotics, because it states that semiosis exists in every living cell, and since it is based on the idea that signs and codes are physical constraints, it can be referred to as physical-constraint biosemiotics, or, more simply, as physical biosemiotics (Pattee himself, in a private correspondence with the author, has accepted that this is an adequate name for his approach).

\section{Darwinian Biosemiotics}

According to the Modern Synthesis, life does not require new laws of physics, but does require a new principle of nature because it is based on natural selection, and this is a process that does not exist in the inanimate world. The principle of natural selection is unique to life, and represents something "extra" in respect to the laws of physics. The Modern Synthesis, in short, takes as explanatory principles not the laws of physics alone, but the laws of physics plus the principle of natural selection.

Ernst Mayr, one of the architects of the Modern Synthesis, has repeatedly emphasized that biology has necessarily a wider framework than physics: “...The explanatory equipment of the physical sciences is insufficient to explain the interplay 
between historically acquired information and the responses of the genetic program to the physical world... This is why it is just as impossible to include biology in physics as it is to include physics in geometry." (Mayr 1982).

The need to add natural selection to the laws of physics, was accepted by Howard Pattee, and this is a step that amounts to an extended version of his theory. Pattee underlined that there is no contrast between physical biosemiotics and natural selection, and we can therefore put them together. In this way, by adding a mechanism of evolution to physical biosemiotics, this becomes evolutionary physical biosemiotics, and since the mechanism in question is natural selection we can rightly call it Darwinian biosemiotics.

This view is in complete agreement with the Modern Synthesis because it accepts all its basic concepts, in particular the model that every organism is a duality of genotype and phenotype and the idea that natural selection is the sole mechanism of evolution. Darwinian biosemiotics, in other words, is physical biosemiotics plus the principle of natural selection, and can be regarded as the evolutionary version of physical biosemiotics.

In both cases, the Pattee approach introduces semiosis into the Modern Synthesis without changing its defining principles, and represents, to all effects, an updating of the Synthesis itself, an extension that allows it to incorporate the concepts of semiosis and recognize at last the existence of "symbols that control matter" in every cell of the living world.

Another approach that can be referred to as 'Darwinian Biosemiotics' is that proposed by Terrence Deacon with three distinct models that attempt a synthesis of the views of Darwin and Peirce. The first is the 'Symbolic Species' model on the origin of language (Deacon 1997), the second is the 'autocell hypothesis' on the origin of life (Deacon 2006), and the third is a comparison of natural selection with the two concepts of entropy proposed by Boltzmann and by Shannon (Deacon 2007, 2008).

\section{Zoosemiotics}

The idea that animals have feelings, psychologies and even minds has been entertained in various ways throughout the centuries, but for a long time it has been taken almost for granted that only man is a semiotic creature, i.e., that only man makes use of signs. This idea was explicitly challenged for the first time in 1963, when Thomas Sebeok suggested that animal communication is also based on signs and proposed the term zoosemiotics for the new science of animal semiosis (Sebeok 1963, 1972).

That proposal set Sebeok out on a long search for evidence of semiosis in the various fields of the life sciences, and eventually the hunt paid off. In the account of his life-long chase that he wrote in 2001, Sebeok declared that he got the crucial experimental clues from three men: Heini Hediger (1908-1992), Giorgio Prodi (1929-1988), and, above all, Jakob von Uexküll (1864-1944). The first two he met personally, while the encounter with Jakob came from reading, in 1976, the original German edition of Theoretische Biologie (1928). That book convinced Sebeok that von Uexküll had already provided abundant evidence of semiosis in the animal world, and had been in fact the unwitting founding father of zoosemiotics. 
Sebeok labelled von Uexküll "one of the greatest cryptosemioticians in the whole world", and in 1977 delivered a powerful speech on 'Neglected figures in the history of semiotic enquiry' at a congress in Vienna. Thure von Uexküll (Jakob's son) was among the audience and thence began a life-long collaboration between the two men, as a result of which the work of Jacob von Uexküll was literally rescued from oblivion and brought to the attention of the world as the foundational basis of zoosemiotics.

In 1979 Sebeok invited Giorgio Prodi to join in the discussions with Thure von Uexküll and that set in motion a further expansion of the field. Prodi suggested that a primitive form of semiosis exists also in molecules and cells and gave it the name of protosemiosis, or natural semiosis (Prodi 1988). The extension of semiosis beyond the animal world gained further momentum in 1981, when Martin Krampen (1981) argued that plants too engage in semiosis (phytosemiotics), and in 1988, when Sorin Sonea (1988) proposed that semiosis goes on even in the bacterial world. The word 'zoosemiotics' became increasingly inadequate, and eventually Sebeok replaced it officially with 'biosemiotics', a term proposed for the first time by Friedrich Rothschild, who used it to illustrate a new approach to psychology (Rothschild 1962), and reproposed, with different meanings, by Juri Stepanov and by Marcel Florkin (Stepanov 1971; Florkin 1974).

Another result of the collaboration between Thomas Sebeok and Thure von Uexküll was the organization of a series of international meetings that took place in Germany, in the late 1980s and early 1990s, at the Glotterbad Clinic for Rehabilitative Medicine at Glottertal, near Freiburg. It was in one of those meetings, in 1990, that Sebeok met Jesper Hoffmeyer, a Danish biochemist who had founded a Society for the Semiotics of Nature in Copenhagen, and shortly afterwards, in 1992, came the encounter with Kalevi Kull, who was organizing the Jakob von Uexküll Centre in Tartu, Estonia.

Hoffmeyer and Kull were biologists, not semioticians, and their joining in turned biosemiotics into a fully interdisciplinary enterprise that started attracting the attention of an increasing number of scientists. It also marked the transition to a younger generation, and perhaps it is fair to say that the passing of the testimonial from Sebeok to Hoffmeyer was formally completed in 2001, when the first Gathering exclusively dedicated to biosemiotics was organized by Hoffmeyer in Copenhagen (Kull 2001; Favareau 2007).

\section{Sign Biosemiotics}

The name of Thomas Sebeok is inseparably associated with zoosemiotics and biosemiotics, but his greatest achievement was probably the revolution that he brought about in semiotics itself. In order to appreciate this point, we must briefly go back to the 1960s and recall that in that period semiotics was a deeply divided field, virtually on the edge of anarchy. The main reason is that it was split into two major schools that were divided about the very concept of sign. One was the school of the Swiss linguist Ferdinand de Saussure (1916), who gave the name semiology to the study of signs and described it as a branch of psychology. The other was the school of the American philosopher Charles Sanders Peirce (1906), who adopted the name semiotics and regarded it as part of philosophy, more precisely as a branch of logic. 
The main difference between the two schools is that Saussure defined the sign as a dual entity, a combination of signifier and signified, whereas Peirce insisted that it is a triadic relationship between a sign vehicle, an object and an interpretant. According to Peirce, any elementary act of signification, i.e., any semiosis, cannot involve less than three entities because there must necessarily be a process of interpretation between sign and meaning.

The semiological tradition of Saussure was followed by Roman Jakobson (18961982), Louis Hjelmslev (1899-1966), Claude Lévi-Strauss (1908), Roland Barthes (1915-1980), Yuri Lotman (1922-1993), Umberto Eco (1932) and in general by the supporters of structuralism. The main followers of Peirce were Ivor Richards (18931979), Charles Ogden (1989-1957), Charles Morris (1901-1979), Thomas Sebeok (1920-2001), John Deely (1942), Marcel Danesi (1946), and in general the proponents of pragmatism. The split seemed to cut also between Europeans (largely on Saussure's side) and Americans (generally pro Peirce), and within each camp there seemed to be an unlimited number of individual approaches.

By the 1990s, however, the situation was totally different. The most authoritative treatise on semiotics, published in four volumes between 1997 and 2003 by Roland Posner, Klaus Robering and Thomas Sebeok, makes it clear that at that time semiotics had become a virtually unified field, and that semiosis was defined in unmistakably Peircean terms. This result had largely been engineered by Sebeok, who promoted it with all the academic and editorial power he could muster as editor-in-chief of Semiotica and founding member of the International Association for Semiotic Studies. That was Sebeok's revolution, and today semiotics is still largely identified with Peircean semiotics, which means that the concept of sign is still usually based on interpretation.

As a result of Sebeok's revolution in semiotics, it has been taken almost for granted that the extension of semiosis, first to the animal world and then to the entire living world, is nothing but the extension of the Peirce view of semiosis to life. Sebeok (2001) expressed this concept in no uncertain terms: "Because there can be no semiosis without interpretability - surely life's cardinal propensity - semiosis presupposes the axiomatic identity of the semiosphere with the biosphere".

The identification of biological semiosis with Peircean semiosis was advanced also by Jesper Hoffemeyer in Signs of Meaning in the Universe, the book where he condensed his manifesto in the statement that "the basic unit of life is the sign, not the molecule" (Hoffmeyer 1996; Emmeche and Hoffmeyer 1991). There was therefore a genuine continuity from Sebeok to Hoffmeyer, and their biosemiotics, being squarely based on the Peirce's concept of sign, can be referred to as sign-based biosemiotics, or, more simply, as sign biosemiotics.

The doctrine of Peirce has been a continuous object of study in this school, and its implications for biosemiotics have recently been analyzed at length in books such as Diagrammatology by Frederik Stjernfelt (2007), Cybersemiotics by Søren Brier (2008) and Biosemiotics by Jesper Hoffmeyer (Hoffmeyer 2008a).

\section{Hermeneutic Biosemiotics}

In Readers of the Book of Life (2002), Anton Markoš has proposed a view of the living world that is based on interpretation, like sign biosemiotics, but that was 
inspired by the hermeneutic philosophy of Martin Heidegger and Hans Georg Gadamer, and has become known as biohermeneutics or hermeneutic biosemiotics (from a historical point of view, the term biohermeneutics was proposed for the first time in 1993 by Sergey Chebanov as an extension to biology of the concepts developed within the Russian school of semiotics) (Chebanov 1993, 1995).

The starting point of Markoš's approach is the problem of 'novelty'. Do genuine novelties exist in nature? Did real novelties appear in the history of life? In classical physics, as formulated, for example, by Laplace, novelty was regarded as a complete illusion, and even if this extreme form of determinism has been abandoned by modern science, the idea that nothing really new happens in the world is still with us. It comes from the idea that everything is subject to the immutable laws of nature, and must therefore be the predictable result of such laws. There can be change in the course of time, but only relative change, not absolute novelties.

Against this view, Markoš underlined that in human affairs we do observe real change, because our history is ruled by contingency, and entities like literature and poetry show that creativity does exist in the world. He maintained that this creative view of human history can be extended to all living creatures, and argued that this is precisely what Darwin's revolution was about. It was the introduction of contingency in the history of life, the idea that all living organisms, and not just humans, are subjects, individual agents which act on the world and which take care of themselves. Darwin did pay lip service to the determinism of classical physics, but what he was saying is that evolution is but a long sequence of "just so stories", not a preordained unfolding of events dictated by immutable laws (Markoš et al. 2007; Markoš et al. 2009).

According to Markoš, the present version of Darwinism that we call the Modern Synthesis, or Neo-Darwinism, is a substantial manipulation of the original view of Darwin, because it is an attempt to explain the irrationality of history with the rational combination and recombination of chemical entities. Cultural terms like information and meaning have been extended to the whole living world, but have suffered a drastic degradation in the process. Information has become an expression of statistical probability, and meaning has been excluded tout court from science.

Darwin has shown that the history of life is as contingent as the history of man, and Heidegger has shown that man can create genuine novelties because he can interpret what goes on in the world. From these two insights, Markoš concludes that all living creatures are interpreting subjects, and that all novelties of the history of life were brought into existence by acts of interpretation.

He argues that we should go back to the basic concepts of the humanities and study the history of life as a 'narrative', precisely as we study the history of human affairs. Hermeneutic biosemiotics in this way calls for a radical new synthesis of biology and semiotics, a synthesis where biology transcends, or leaves behind, the objective world of science and becomes an extension of the humanities.

\section{Code Biosemiotics}

In The Semantic Theory of Evolution (1985) Marcello Barbieri proposed that natural selection and natural conventions are two distinct mechanisms of evolution because information and meaning are two distinct components of life. Natural selection is the 
long term result of copying, whereas natural conventions are the long term result of coding, and the two mechanisms are distinct because coding cannot be reduced to copying (proteins cannot be copied). This is a version of biosemiotics that can be referred to as code-based biosemiotics, or more simply, as code biosemiotics because it assumes that semiosis is defined by coding not by interpretation. The main reason for this conclusion is that the rules of the genetic code have been virtually the same in all living systems and in all environments ever since the origin of life, which clearly shows that they do not depend on interpretation.

There was however a major problem with this view: if semiosis is as fundamental in life as it is in culture, why is it that we find only the genetic code in nature, whereas in culture we have an unlimited number of codes? The logic of code biosemiotics predicts that there must be many other organic codes in the living world, and this is a testable hypothesis because it has precise experimental consequences. A code is a correspondence between the objects of two independent worlds, and any organic code requires therefore molecules that perform two independent recognition processes. These molecules are called adaptors, and their presence is what actually proves the existence of a code. The adaptors of the genetic code, for example, are the transferRNA, and it was the discovery of these molecules that led to the discovery of the genetic code. Barbieri argued that adaptors must exist in many other processes, and showed that this is actually the case. True adaptors, for example, exist in splicing and in signal transduction, and that proves that those processes are based on splicing codes and on signal transduction codes (Barbieri 1998, 2003a).

The discovery of the organic codes has been made also with other criteria, but in all cases it has been the result of experimental data. They include the sequence codes (Trifonov 1987, 1989; 1996; 1999), the cytoskeleton codes, the compartment codes (Barbieri 2003a), the adhesive code (Readies and Takeichi 1996; Shapiro and Colman 1999), the sugar code (Gabius 2000; Gabius et al. 2002), the histone code (Strahl and Allis 2000; Turner 2000; 2002; Gamble and Freedman 2002), and many others (Barbieri 2008). This is the experimental basis of biosemiotics, the great novelties that biosemiotics has in store for the life sciences.

According to modern biology, the genetic code appeared at the beginning of the history of life and the cultural codes at the end of it, but there was nothing in between, no other organic code in 4 billion years of evolution. Code biosemiotics reveals instead that the history of life has been full of organic codes and this gives us a completely new description and a new understanding of that history. It makes us realize, in particular, that the great events of macroevolution were associated with the appearance of new organic codes, and this is a totally new explanation of the causes of evolution.

Code biosemiotics, in conclusion, is a theoretical framework that was developed from the 1980s to the 1990s in parallel with, and in complete independence from, the Sebeok-Hoffmeyer approach, and claims that the organic codes are the great experimental facts of life which are not accounted for by modern biology.

\section{The First Step Towards Unification}

The various schools of biosemiotics developed their approaches independently and went along separate roads for at least three decades, from the late 1960s to the end of 
the 1990s. Eventually, however, contacts were established and people started talking to each other and comparing notes.

The first steps toward unification came in 2004, at the fourth Gathering in Biosemiotics organized by Anton Markoš in Prague. Jesper Hoffmeyer, Claus Emmeche, Kalevi Kull, Anton Markoš and Marcello Barbieri decided that what was uniting them — the introduction of meaning in biology — was far more important than their divisions. Up until then, Barbieri had referred to the science of biological semiosis as semantic biology, or biosemantics, whereas Markoš had called it biohermeneutics, but they both agreed to give up their favourite names and to adopt the term biosemiotics that Thomas Sebeok had been campaigning for with so much passion and vigour. That is when biosemiotics really came of age. It happened when people decided to work together not because they had identical ideas but because they accepted to put their differences aside in the interest of a greater goal.

The existence of semiosis in life does not exclude, in principle, the existence of semiosis in inanimate matter, but the unifying idea of Prague was the concept, proposed by Thomas Sebeok, that "life and semioisis are coextensive", i.e. that "semiosis exists in all living beings and only in living beings". This became "the foundational principle' of biosemiotics, and it was precisely its acceptance that realized the first step towards unification. It must be underlined that this principle is a scientific hypothesis because it is falsifiable (a single example of semiosis in inanimate matter would immediately falsify it).

Today there are still differences between the schools, but there is also a 'minimal unity' in the field because of two basic principles, or postulates, that are accepted by virtually all biosemioticians.

(1) The first postulate is Thomas Sebeok's idea that "life and semioisis are coextensive". This implies that semiosis appeared at the origin of life, and sharply differentiates biosemiotics from 'pansemiotics' and 'physiosemiotics', the doctrines that semiosis exists also in inanimate matter and therefore everywhere in the universe. It also differentiates it from the views that semiosis exists only in animals or only in humans beings.

(2) The second postulate is the idea that signs, meanings and codes are natural entities. This sharply divides biosemiotics from the doctrine of 'intelligent design', and from all other doctrines that maintain that the origin of life on Earth was necessarily the product of a supernatural agency.

At the 2004 Gathering in Prague it was acknowledged that these two postulates amount to a definition of biosemiotics, in the sense that they are both necessary and sufficient to establish the study of biological semiosis as a natural science. Within this common theoretical framework, the various schools continue to pursue separate approaches, but this is only natural in a young science. What really matters is that they have the same final goal of exploring, by different routes, the semiotic dimension of life.

\section{Precursors and Contributors}

The discovery of the genetic code was the foundational event of biosemiotics, because it made it possible to conceive, for the very first time in the history of 
biology, that semiosis exists at the cellular level. It is true that the evidence of the code did not seem sufficient, on its own, to prove that idea, but there is little doubt that without the genetic code there would be no study of cellular semiosis.

Before the discovery of the code, however, there were a few people who prepared the ground by introducing concepts that later on played a crucial role in biosemiotics. Here, again, the difference between the schools is critical: Charles Peirce and Jakob von Uexküll were the acknowledged precursors of sign biosemiotics; Martin Heidegger and Hans-Georg Gadamer inspired hermeneutic biosemiotics; Erwin Schrödinger and John von Neumann were the precursors of both physical biosemiotics and code biosemiotics.

After the discovery of the genetic code, furthermore, a number of people introduced concepts that were related to biosemiotics without using the terminology of that field, and without being associated with any of its schools. They too had a semiotic approach to life and were, to all effects, contributors to biosemiotics, because they were concerned with the study of information and meaning in life, and not with the study of information alone.

(1) Gregory Bateson (1904-1980) maintained that evolution cannot be understood without taking into account intelligence and 'learning' (Bateson 1972, 1979) and although he never used the term 'biosemiotics' he introduced a number of concepts that are still considered fundamental by many biosemioticians. Among these are: the cybernetic distinction between "creatura and pleroma" (living and inanimate); the constant interplay between "analog and digital codings" in living systems; the principle of "double description"; the theme that "the map is not the territory"; the concept of "the pattern that connects"; and, above all, the idea that information is "a difference that makes a difference" These ideas are the legacy of Gregory Bateson and to many people they represent an ongoing field of research and a continuous source of inspiration for biosemiotics (Hoffmeyer 2008b).

(2) Since the 1960s, Allen Newell (1927-1992) and Herbert Simon (1916-2001) developed the idea that 'problem-solving agents' are, first, physical entities and, second, sign-using systems. They were concerned with the issue of "problem solving" (or "decision theory") in a wide variety of fields, from economics and political science to cognitive psychology and artificial intelligence, but their approach clearly applies also to living systems, since these are the quintessential problem-solving agents. According to Newell and Simon, living systems must necessarily be 'sign-using systems', and this is undoubtedly a biosemiotic idea (Simon 1962, 1973; Newell and Simon 1972; Newell 1980).

(3) The development of information theory has proved that telecommunications are necessarily based on error-correcting codes, and some scientists (Battail 2006, 2007; Gonzalez 2008) have argued that similar codes must exist in living systems. As with the approach of Newel and Simon, this is an indirect but important contribution to biosemiotics because it underlines the distinction between information and meaning, and points out that signs and codes are essential components of all problem-solving systems.

(4) Günther Witzany $(1995,2000,2006)$ has recently proposed a "pragmatic turn" in the study of life by emphasizing that the meaning of a sign is not determined 
only by syntax and semantics, but ultimately by pragmatics. This concept, inspired by Wittgenstein's Philosophical Investigations ("the meaning of a word is its usage"), by Austin's "How to do things with words", by Searle's speech-act theory, and by Habermas' theory of communicative action, is a contribution to the philosophy of biology and does have implications for biosemiotics, because it implies a link between meaning and utility, or meaning and function.

There have been, in conclusion, a few precursors before the discovery of the genetic code, and a few independent contributors after that discovery, and clearly all of them are part of the history of biosemiotics.

\section{PART 2 - Towards a Unified Science}

\section{The Difference Between Physical and Code Biosemiotics}

Howard Pattee has pointed out that biology does not need new laws of physics because physical theory is based on laws and constraints, and entities like symbols and codes can be regarded as special types of constraints. This is undoubtedly true, but it is not the whole truth. Physical theory starts with the definition of fundamental quantities, or elementary observables (time, space, mass etc), and then looks for relationships between them which are referred to as laws and constraints. The basic components of physical theory, in short, are not two but three: laws, constraints, and observables.

The important point here is that the history of physics has not been made only by the discovery of new laws and new constraints, but also by the discovery of new observables. In Newton's physics, for example, the fundamental observables were time, space and mass, but then electricity required the addition of electric charge and thermodynamics required the addition of temperature.

If we assume a priori that life does not need new observables, we can limit ourselves to laws and constraints, and that takes us down the road that leads to physical biosemiotics. But that is precisely the point that we cannot take for granted. Life is based on copying and coding and these processes bring into existence entities like sequences and codes (or organic information and organic meaning) which have all the defining characteristics of fundamental observables. This is because the role of observables is to allow us to describe the world and we simply cannot describe living systems without sequences and codes, nor can we regard them as physical quantities because they cannot be measured. Organic information and organic meaning, on the other hand, are as objective and reproducible as physical quantities and belong therefore to the category of the fundamental observables that allow us to describe the world. More precisely, they are a new type of fundamental entities that have been referred to as nominable entities (Barbieri 2003b, 2004).

Howard Pattee has repeatedly underlined that "life can only be described in the language of physics as special constraints" and that "there are no fundamental principles beyond laws, constraints and natural selection" (Pattee 2001, 2008). This means that natural selection is regarded as a 'special' constraint, but what is it that makes it 'special', i.e. different from the 'ordinary' constraints that operate in the 
inanimate world? Physical biosemiotics, furthermore, states that information and meaning are constraints, but it does not say what the difference between them is.

Code biosemiotics accepts that information and meaning are constraints, but points out that they are also the result of processes which bring new fundamental entities into existence. And it is precisely these 'extra' entities that distinguish the processes in question from ordinary constraints and make them 'special'. Natural selection, for example, has rightly been 'added' to the laws and constraints of physics, but this addition is justified only because natural selection is based on molecular copying, and copying brings a new observable (organic information) into existence. Without a new observable there would be no reason to regard natural selection as a special type of constraint, so it is the new observable that makes the difference. And the same is true for the natural conventions. They too can be regarded as constraints, but what makes them 'special' is that they bring into existence new observables like signs, meanings and coding rules.

Code biosemiotics, in conclusion, is distinct from physical biosemiotics because it maintains that copying and coding bring new fundamental observables into existence. A second difference is that it describes the cell as a trinity of genotype, phenotype and ribotype, not as a duality of genotype and phenotype (Barbieri 1981). A third difference is that code biosemiotics recognizes the existence of a new mechanism of evolution (natural conventions), and states that the great steps of macroevolution were produced by the appearance of new organic codes (Barbieri 1985, 1998, 2003a).

\section{The Difference Between Code and Sign Biosemiotics}

Semiosis is based on coding in code biosemiotics and on interpretation in sign biosemiotics, but this is only part of difference that exists between the two schools. In order to appreciate in full the divide that separates them, we need to go back to the difference that exists between the organic codes of the cell and the man-made codes of culture.

The genetic code is often compared to the Morse code because both can be described by a set of 'transformation rules', but in reality this is only a superficial analogy. For one thing, the Morse code is perfectly reversible, or invertible. It transforms the letters of the alphabet into dots and dashes and, vice versa, dots-anddashes into letters of the alphabet, whereas nothing of the kind takes place in the cell. The genetic code is absolutely irreversible, or non-invertible. It goes from genes to proteins and absolutely not viceversa. The reverse transformation is not just avoided, it is physically impossible. Another major difference is that the messages written in Morse are perfectly equivalent to those of the Alphabet world. They carry exactly the same information and are simply two different ways of expressing the same reality. The Morse code, in short, transforms a world of entities into a world of equivalent entities. In the case of the genetic code, instead, the situation is totally different. Genes and proteins are not at all equivalent objects, they belong to completely different worlds. This is because protein synthesis is not just a semiosis, but a manufacturing semiosis, i.e., a type of semiosis whose function is to produce objects that cannot come into existence in any other way (the manufacturing processes of the cell should not be assimilated to those of our machines because cells have an internal codemaker whereas in our machines the codemaker is outside them). 
Another example of manufacturing semioisis is splicing, the process that cuts RNAs pieces from primary transcripts and assembles the remaining pieces into messenger RNAs. There are however other types of semiosis in the cell that do not have a manufacturing function. Signal transduction, for example, is a semiosis because it creates a correspondence between first and second messengers by means of receptor molecules that have all the defining features of adaptors, but it is not a manufacturing semiosis because the second messengers already exist in the cell and are not manufactured by the transduction process. Signal transduction has the function of creating a specific signalling association between first and second messengers and is therefore a semiosis that can be referred to as signalling semiosis.

Another example of signalling semiosis is given by the compartment codes of the eukaryotic cells. In this case too we recognize the existence of semiosis by the presence of adaptors, and we realize that its function is to create specific signalling associations between pre-existing objects, not to bring these objects into existence. The function of signalling semiosis, in short, is totally different from that of manufacturing semiosis, but it is equally fundamental to life. Manufacturing semiosis is about generating objects, whereas signalling semiosis is about organizing them into functioning structures.

The presence of these two types of semiosis can also be recognized at many other levels of organization. Mental objects, for example, are brought into existence by manufacturing mental processes (Barbieri 2006a), and once in existence they are organized into mental structures by signalling processes. Manufacturing semiosis and signalling semiosis exist and have complementary functions at many levels of organizations, and must have evolved together again and again in the history of life.

For a long time it has been assumed that the function of semiosis is to interpret the world, but this is not the whole truth. We must acknowledge that in addition to interpretive semiosis there are two other types of semiosis whose function is not to interpret the world of life but to create it, to bring its objects into existence and to organize them into functioning wholes.

Life is essentially about three things: (1) it is about manufacturing objects, (2) it is about assembling objects into functioning structures, and (3) it is about interpreting the world. The discovery that these are all semiotic processes, tells us that life depends on semiosis much more deeply and extensively than we thought on the basis of the interpretive semiotics of Peirce. This approach, in other words, is not wrong, but is too limited, too restrictive. There are three distinct types of semiosis in Nature and interpretive semiosis is only one of them.

This is the great difference between the above schools of biosemiotics. Sign biosemiotics is based on the Peircean approach and assumes that semiosis is about interpreting the world. Code biosemiotics is based on the code model and assumes that semiosis is primarily about bringing objects into existence and organizing them into functioning structures.

\section{The Difference Between Hermeneutic and Code Biosemiotics}

The idea that interpretation is the quintessential feature of semiosis is typical not only of sign biosemiotics, but also of hermeneutic biosemiotics. From this point of 
view, the two schools are very close, and the major argument of code biosemiotics the idea that life is much more than interpreting the world — is equally applicable to both of them.

Hermeneutic biosemiotics, however, is not based on Peirce's model and has a number of characteristics of its own that present a direct challenge to code biosemiotics. Markoš acknowledged the existence of organic codes in life, but underlined that: "Meaning, stripped off its hermeneutical dimensions, produced according to rules, becomes the simple decoding of signals. This reduction to a stimulus/response scheme is but a pale ghost of how meaning is generally understood by common sense, not to speak of hermeneutics or poetry!"' (Markoš and Cvrčková 2002).

Anton Markoš claims that organic codes are not enough for semiosis. What turns living creatures into semiotic systems is their ability to interpret the world, and single cells, according to Markoš, have this ability because their behaviour is contextdependent. This is why even single cells are subjects, not objects, and this is why we recognize them as living creatures, not machines (Markoš 2004).

The idea that single cells are capable of interpretation is deduced by the fact that their behaviour is context-dependent, but this is not at all a foregone conclusion. A context-dependent behaviour means a context-dependent expression of genes, and this is obtained by linking the expression of genes to signal transduction, i.e. by integrating the genetic code with a signal transduction code. And if it takes only two context-free codes to produce a context-dependent behaviour, one can only wonder at the more sophisticated types of behaviour that were developed during the evolution of single cells by the acquisition of new codes such as cytoskeleton codes, histone codes, migration codes, compartment codes and the like. Coding and decoding are far simpler than interpretation, and there is no need to assume anything more complicated than that in single cells, especially in those that appeared at the beginning of the history of life.

As for the argument that meaning cannot be reduced to coding, because living beings are not machines, it should be noticed that the automatic application of coding rules does not at all imply a loss of creativity. The rules of grammar and syntax in language, for example, are executed automatically every time that we speak and write, and yet it is precisely that automatism that allows us to create those endlessly different combinations of words that we call literature and poetry.

Let us now turn to the major theme of hermeneutic biosemiotics, the call for a humanistic biology, i.e. for a biology that transcends science. There is no doubt that contingency exists in evolution, so we do need a narrative approach to the history of life, but we also need to take into account the mechanisms of copying and coding in our narratives. Those mechanisms exist, they are experimental realities, and narratives with mechanisms have a far greater content of 'truth' than narratives without them, because mechanisms establish relations of cause and effect and that is what understanding is all about.

Hermeneutic biosemiotics, in conclusion, wants to turn biology into a field of the humanities, whereas code biosemiotics wants to keep it within science, because meaning is a natural entity and we must introduce it in science just as we have introduced the concepts of energy and information. And this is not because science is superior to the humanities. It is because organic meaning exists in the organic world just as cultural meaning exists in the cultural world. A true synthesis of 
biology and semiotics, in short, cannot be the reduction of one to the other. It can only be the realization that there is no unbridgeable divide between them.

\section{Two Models of Semiosis}

Any field of research relies on models, and in biosemiotics there are, today, two distinct models of semiosis: one based on interpretation, and one based on coding. They can be summarized in the following way.

(1) The Interpretation model was described in the treatise of Semiotics edited by Posner, Robering and Sebeok, and states that: "The necessary and sufficient condition for something to be a semiosis is that A interprets $\mathrm{B}$ as representing $\mathrm{C}$, where $\mathrm{A}$ is the interpretant, $\mathrm{B}$ is an object and $\mathrm{C}$ is the meaning that $\mathrm{A}$ assigns to B" (Posner et al. 1997).

(2) The Code model states that: "The necessary and sufficient condition for something to be a semiosis is that A provides a conventional association between $\mathrm{B}$ and $\mathrm{C}$, where $\mathrm{A}$ is a set of adaptors and $\mathrm{B}$ and $\mathrm{C}$ are the objects of two independent worlds (Barbieri 2003a, 2006b).

In general, different models tend to exclude each other, but in this case they are in fact complementary and both contain some truth. More precisely, the code model is valid in single cells because organic codes exist in them, and a combination of different organic codes is enough to explain the context-dependent behaviour of these cells. At the same time, the interpretation model is valid throughout the whole animal kingdom because there is ample evidence that all animals are capable of interpreting the world.

All this takes us to the conclusion that the history of life can be divided into two great periods. In the first three billion years of this history, the Earth was populated only by single cells, and biological semiosis was based exclusively on coding (organic semiosis). In the last 600 million years or so, animals appeared on our planet and their evolution gave origin to a new form of semiosis that was based on interpretation (interpretive semiosis).

Can we justify this conclusion? Can we say that there has been a real macroevolutionary discontinuity between single cells and animals? To this purpose, let us underline that the mind - or the brain - of animals does not interpret the world but only representations of the world. Any interpretation, in short, is always exercised on internal models of the environment, never on the environment itself.

Single cells, on the other hand, do not build representations. They decode the signals from the environment but do not build internal models of it and therefore cannot interpret them. They are sensitive to light, but do not 'see'; they react to sounds but do not 'hear'; they detect hormones but do not 'smell and do not 'taste' them. It takes the cooperation of many cells which have undertaken specific processes of differentiation to allow a system to see, hear, smell and taste, so it is only multicellular creatures that have these experiences.

Only animals, in short, build representations of the world and only these representations allow them to perceive, to feel, and to interpret the world. The evolution from single cells to animals was far more than an increase in growth and complexity. It was a true macroevolutionary event that gave origin to absolute 
novelties, to entities that had never existed before such as perceptions and feelings. Interpretation had an origin and a history, like everything else in life, and appeared only in multicellular systems. That is what really divides animals from single cells, and that is why there are at least two distinct types of semiosis in the living world (the term "single cells" is used here in the sense of "components of monocellular systems", i.e., systems formed by cells that are physically separated from each other. It is does not mean cells living in isolation).

\section{Coding and Interpretation}

Animals build representations (or internal models) of the world whereas single cells cannot physically do that. This implies the existence of two distinct types of semiosis, one based on interpretation and one based on coding, and it is possible to show that this distinction is real because it is based on objective criteria. In order to prove this point we have to go back to the concept of meaning, and to a classic distinction introduced by Gottlob Frege.

The meaning of a sign is, by definition, what the sign stands for, but this can be of two very different types. A sign can stand for an object that is 'external' or 'internal' to the system. The difference between these two types of meaning was outlined by Frege with an example that is reported in virtually every discussion of this issue.

Frege pointed out that the terms "Morning Star" and "Evening Star" both indicate the planet Venus, and have therefore the same 'external' meaning, but very different 'internal' meanings. The "Evening Star" is visible at dusk and was related to end-ofthe-day events, whereas the "Morning Star" was related to the rise of the sun and to the beginning of a new day (Frege 1892).

In order to differentiate between external and internal meanings, Frege gave them two different names. He called them respectively 'reference' and 'sense'. Other authors have adopted a different terminology, and have used terms like 'extension' and 'intension', or 'denotation' and 'connotation'. The point, however, is the same. All entities associated to signs by conventions qualify as meanings, but some may refer to outside objects (reference) and others to internal entities (sense).

After Frege, it has been taken virtually for granted that all signs have both types of meanings, but this is not always the case. Proteins, for example, are built according to the genetic code, and this is a set of exclusively internal rules. Proteins do not have any other meanings in addition to those that come from genes, and this implies that the apparatus of protein synthesis is a system of signs which have sense but not reference, i.e., signs which have internal meanings but not external ones. The same is true for all the organic codes that exist in single cells. They are sets of rules that have sense but not reference. This may appear surprising, at first, but it does have a natural explanation.

The human mind (or brain) receives signals from the environment and uses them to produce internal models of the world, models that are the reference, the external meanings, that the mind associates to the incoming signals. The mind, however, is also giving internal meanings to signs, and must integrate them with the external meanings in order to allow the body to react to the incoming signals. This makes us understand why the mind (or the brain) must necessarily use two types of meanings. 
If the mind could act directly on the environmental signals, there would be no need of external meanings, but that is not what happens. The mind can only act on representations of the world and that is why it must use signs which have both internal and external meanings, i.e., sense and reference.

There is, in short, an objective difference between the semiosis of single cells and that of animals. A semiosis based on coding requires only one type of meaning (sense) whereas a semiosis based on interpretation requires two distinct types of meaning (sense and reference).

\section{The Origins of Semiosis}

The origin of life took place when the first molecular machines started producing genes and proteins by copying and coding (Barbieri 1981, 1985, 2003a, 2008). But copying and coding bring sequences and conventions into existence and are therefore semiotic processes. This is why we can say that the origin of life was also the origin of semiosis, and viceversa. The organic codes of single cells appeared in the first three billion years of life's history, during the period of cellular evolution, and were involved either in manufacturing semiosis or in signalling semiosis. With the origin of animals, however, a third type of semiosis came into being, a type that is referred to as interpretive semiosis because it is specifically involved in the process of interpretation.

The first animals were probably organisms whose behaviour was almost entirely programmed by genes, but there was a limit to the number of instructions that can be carried in a genome, and that set the stage for the evolution of a new type of behaviour. Since the number of hard-wired responses could not grow indefinitely, animals started resorting to processes of learning in order to increase their behavioural repertoire.

Learning how to respond to a signal, on the other hand, means learning how to interpret that signal, and this means that interpretation is not only a context-dependent but also a learning-dependent process. At the same time, learning requires a memory where the results of experience are accumulated and this means that interpretation is also a memory-dependent process. Finally, interpretation requires a comparison of incoming signals with an internal reference, and this can take place only in systems that build internal representations of the world. Interpretation, in short, is a semiosis, because it is process that gives meaning to signs, but it is a new type of semiosis. It is context-dependent, like decoding, but it is much more complex than decoding because it requires learning, memory and internal representations of the world.

Animals became capable of interpreting the world because they could build internal representations of it, and this is a process that single cells simply cannot do. Interpretation is essentially what Peirce called an 'abduction', a process that is neither induction nor deduction, but a 'rule of thumb' way of creating a link between observations and explanations (Peirce 1906). More precisely, animals learned to interpret the world by using the two types of signs that Peirce called 'icons' and 'indexes'. They did not, however, use the third type of sign, the 'symbols'. Only our species managed to do that, and developed a third type of semiosis that was based on symbolic codes shared by all members of a community, i.e., on language (Deacon 1997). 
The evolution of semiosis was characterized therefore by three great innovations: (1) the origin of organic semiosis (the semiotic threshold), (2) the origin of interpretive semiosis (the hermeneutic threshold), and (3) the origin of linguistic semiosis (the cultural threshold).

The origin of organic semiosis and the origin of interpretation were separated by three billion years of cellular evolution, because interpretation is dependent on internal models of the world, and probably evolved only in animals. The origin of language came after another five hundred million years and apparently evolved only in our species. The history of semiosis, in conclusion, was a process that started with contextfree codes and produced codes that were more and more complex. Today, our cultural codes are so heavily dependent on context, learning, memory and representations that we can hardly imagine semiosis without interpretation, and yet these are distinct processes and we need to keep them apart if we want to understand them.

\section{The Second Step Towards Unification: General Biosemiotics}

The foundational principle of biosemiotics is Thomas Sebeok's idea that "life and semiosis are coextensive". With this principle, Sebeok extended semiosis from the animal world to all living creatures, but in addition to this 'first' extension, he proposed also a 'second' extension by claiming that all living creatures are capable of interpretation. He did this because he believed that semiosis is always linked to interpretation, but now we have seen that there a difference between coding semiosis and interpretive semiosis, so we need to keep them apart. This is important, because only this separation allows us to show that the foundational principle of biosemiotics is in agreement with all the evidence of modern biology.

The existence of the organic codes allows us to conclude that coding semiosis exists in all single cells, and therefore that all cells are semiotic systems, a conclusion that every biologists should be able to accept because it is based on experimental evidence. We cannot, however, prove that in single cells there is also a semiosis based on interpretation, and this is why the two types of semiosis must be separated. If we can extend semiosis to all living creatures, in short, it is only because we can prove the existence of coding semiosis in all cells. It is coding semiosis, in other words, not interpretive semiosis, that provides the experimental basis for the foundational principle of biosemiotics.

At this point it may be useful to introduce a new terminology, so let us make the following distinction.

(a) A biosemiotic theory that accepts only one model of semiosis is referred to as Restricted biosemiotics.

(b) A biosemiotic theory that accepts two or more testable models of semiosis is referred to as General biosemiotics.

It will be noticed that General biosemiotics does not specify a priori the number or the type of its models, but it does specify that all of them must be testable, and this for a very good reason. The obvious objection is "why should we accept many models of semiosis when one could be enough? If the term 'interpretation', for example, means 'interpretation' in some cases and 'decoding' in other cases, we would have a single model that applies to everything". And this is precisely the 
point. Such a model would describe everything a priori, by virtue of our definitions, so it is unfalsifiable and tells us nothing about the world. This is why it is imperative that the models of biosemiotics are testable. Only this pre-requisite guarantees that they describe types of semiosis that actually exist in Nature. And only this can convince biologists that biosemiotics is a science, not a philosophy.

The foundation principle of biosemiotics, to start with, is testable because, as we have seen, it can be falsified. The code model and the interpretation model that have been described in this paper are fully testable, and in fact it is precisely because it is testable that the interpretation model has been found valid in animals but not in single cells. The models of manufacturing semiosis, signalling semiosis and interpretive semiosis are also testable, because they are based on characteristics that have direct experimental consequences.

The various schools of biosemiotics will be able to overcome their differences only when they accept the principle that their models must be testable. This, on the other hand, is also the precondition for a scientific biosemiotics, which tells us that building a scientific biosemiotics and a unified biosemiotics is one and the same thing. There can be only one scientific biosemiotics, and whatever it turns out to be we can give it the name of General biosemiotics because it is bound to be based on a plurality of testable models.

\section{The Contribution of Darwinian Biosemiotics}

Any version of biosemiotics that accepts natural selection as the sole mechanism of evolution qualifies as Darwinian biosemiotics, but it must be pointed out that this is only a limited type of biosemiotics. Natural selection is the long term result of the copying of the genes, and copying is the process that produces genetic information, not meaning. In Darwinian biosemiotics, in other words, meaning is at most a qualification of information (something like 'meaningful information') and coding is a by-product of copying, not a distinct mechanism.

The distinction between meaning and information is important, but it may give the false impression that biosemiotics is mostly a debate on terminology, not an enquiry into the real world of life. The crucial issue, instead - let us repeat it - is the existence of the organic codes in nature.

A history of life that has the genetic code at the beginning and the cultural codes at the end, with nothing in between, is very different from a history of life that is full of organic codes. A view of evolution where all major transitions are the result of copying (natural selection) is very different from a view where they are the result of coding (natural conventions). Darwinian biosemiotics gives very little importance to the organic codes, and in this way it has very little novelty to offer. Take away the organic codes, and all you have is the same old view of the world as before.

Howard Pattee has been a pioneer of biosemiotics because he has been the first to explain why "life is matter controlled by symbols", but if this illumination does not "bear fruits", if it does not converge into a general biosemiotics, if it does not show that organic codes exist and change the course of evolution, what do we make of that initial breakthrough? Darwinian biosemiotics has been an important first step, yes, but it cannot remain a first step forever. 
Terrence Deacon (1997) has also given a pioneering contribution to biosemiotics by proposing a theory on the origin of language based on semiotic concepts such as "icons, indexes and symbols". But the real problem, here, is understanding the mechanisms that bring icons, indexes and symbols into existence, and the crucial issue, once again, is the contribution of the organic codes to the generation of the novelties of life.

Another form of Darwinian biosemiotics is that which maintains that the meaning of an object is due to its function, or its utility. In molecular biology, this idea was proposed for the first time in 1974 by Marcel Florkin, with the statement that "A bioseme carries no 'beteutung' (no 'meaning'), because its signifier is a molecular structure and its signified is a biological function." (Florkin 1974). In the long run, it is natural selection that determines what is useful in life, and this is why a definition of meaning in terms of function is very much in agreement with Darwinian biosemiotics.

The characteristic of all these approaches is that meaning is always regarded as a qualification of something else, not as an entity in its own right. But if meaning derives from function, or from information, or from both, why should we bother about it? The concepts of function and information would be enough, and Occam's razor would demand that we get rid of redundant terms such as signs and meanings.

Darwinian biosemiotics and its variants like functional biosemiotics are, in conclusion, theoretical frameworks that consider meaning, semiosis and codes as entities that have little or dubious importance. The recognition of their existence is still a contribution to our understanding of life, but it is a modest one, and does not require any change in the present paradigm of biology.

\section{Conclusion}

Biosemiotics is a new continent whose exploration has just begun, and it is not surprising that people have gone off in different directions. In addition to the difficulties that arise in any new field, however, biosemiotics is also having problems of its own. Today, the major obstacles to its development come from three great sources of confusion.

(1) The first handicap is that biosemiotics is wrongly perceived as a philosophy rather than a science, and in particular as a view that promotes physiosemiotics, pansemiotics, panpsychism and the like. Here, the only solution is to remind people that biosemiotics is a science because it is committed to exploring the world with testable models, like any other scientific discipline.

(2) The second handicap is that biosemiotics appears to be only a different way of looking at the known facts of biology, not a science that brings new facts to light. It is not regarded capable of making predictions and having an experimental field of its own, and to many people all this means irrelevance. Here the only solution is to keep reminding people that the experimental field of biosemiotics is the study of organic codes and signs, that biosemiotics did predict their existence and continues to make predictions, that codes and signs exist at all levels of organization and that the great steps of macroevolution are 
associated with the appearance of new codes. This is what biosemiotics is really about.

(3) The third handicap is the fact that biosemiotics, despite being a small field of research, is split into different schools, which gives the impression that it has no unifying principle. Here we can only point out that a first step towards unification has already been taken and that the conditions for a second, decisive, step already exist. When biosemioticians finally accept that the models of semiosis must be testable, they will also acknowledge the existence of all types of semiosis that are documented by the experimental evidence and that is all that is required to overcome the divisions of the past. At that point, the old divides will no longer make sense and most schools will find it natural to converge into a unified framework.

Biosemiotics must overcome all the above obstacles in order to become a unified science, but this process of growth and development has already started and there is light at the end of the tunnel.

Acknowledgements I wish to thank all the members of the Editorial Team of Biosemiotics for agreeing to read the draft of this paper and to bring to my attention any factual mistakes and inaccurate or misleading statements. Virtually all their suggestions have become part of the final manuscript and have greatly improved its overall quality, to the point that I like to consider this short history as almost a collective enterprise. I am particular grateful to Wendy Wheeler for proofreading the paper and for taking care of it with great skill and enthusiasm.

\section{References}

Barbieri, M. (1981). The ribotype theory on the origin of life. Journal of Theoretical Biology, 91, 545601.

Barbieri, M. (1985). The semantic theory of evolution. London \& New York: Harwood Academic Publishers.

Barbieri, M. (1998). The organic codes. The basic mechanism of macroevolution. Rivista di BiologiaBiology Forum, 91, 481-514.

Barbieri, M. (2003a). The organic codes. An introduction to semantic biology. Cambridge: Cambridge University Press.

Barbieri, M. (2003b). Biology with information and meaning. History and Philosophy of the Life Sciences, $25,243-254$.

Barbieri, M. (2004). The definitions of information and meaning. Two possible boundaries between physics and biology. Rivista di Biologia-Biology Forum, 97, 91-110.

Barbieri, M. (2006a). Semantic biology and the mind-body problem: the theory of the conventional mind. Biological Theory, 1(4), 352-356.

Barbieri, M. (2006b). Life and semiosis: the real nature of information and meaning. Semiotica, 158(1/4), 233-254.

Barbieri, M. (2008). Biosemiotics: a new understanding of life. Naturwissenschaften, 95, 577-599.

Bateson, G. (1972). Steps to an ecology of mind. San Francisco: Chandler.

Bateson, G. (1979). Mind and nature: A necessary unity. New York: EP Dutton.

Battail, G. (2006). Should genetics get an information-theoretic education? IEEE Engineering in Medicine and Biology Magazine, 25(1), 34-45.

Battail, G. (2007). Information theory and error-correcting codes in genetics and biological evolution. In M. Barbieri (Ed.), Introduction to Biosemiotics, pp. 299-345. Dordrecht: Springer.

Beadle, G., \& Beadle, M. (1966). The language of life. An introduction to the science of genetics. New York: Doubleday and Co.

Bohr, N. (1933). Light and life. Nature, 131, 421-457. 
Brier, S. (2008). Cybersemiotics: Why information is not enough. Toronto: University of Toronto Press.

Chebanov, S. (1993). Biology and humanitarian culture: The problem of interpretation in bio-hermneutics and in the hermeneutics of biology. In K. Kull \& T. Tiivel (Eds.), Lectures in Theoretical Biology: Second Stage, pp. 219-248. Tallinn: Estonian Academy of Sciences.

Chebanov, S. (1995). Enlogue as quasipersonal interacton: biohermeneutic issues. European Journal for Semiotic Studies, 7(3-4), 439-466.

Deacon, T. W. (1997). The symbolic species: The co-evolution of language and the brain. New York: Norton.

Deacon, T. W. (2006). Reciprocal linkage between self-organizing processes is sufficient for selfreproduction and evolvability. Biological Theory, 1(2), 136-149.

Deacon, T. W. (2007). Shannon-Boltzmann-Darwin: redefining information (Part I). Cognitive Semiotics, $1(1), 123-147$.

Deacon, T. W. (2008). Shannon-Boltzmann-Darwin: redefining information (Part II). Cognitive Semiotics, 1(2), 168-198.

Emmeche, C., \& Hoffmeyer, J. (1991). From language to nature: the semiotic metaphor in biology. Semiotica, 84(1/2), 1-42.

Favareau, D. (2007). The evolutionary history of biosemiotics. In M. Barbieri (Ed.), Introduction to Biosemiotics, pp. 1-67. Dordrecht: Springer.

Florkin, M. (1974). Concepts of molecular biosemiotics and molecular evolution. In M. Florkin \& E. H. Stotz (Eds.), Comprehensive Biochemistry, Vol. 29A, pp. 1-124. Amsterdam: Elsevier.

Frege, G. (1892). Über Sinn und Bedeutung. Zeitschrift fürPhilosophie und philosophische Kritik, 100: 25-50. In P. Geach \& M. Black (Eds.), Translations from the Philosophical Writings of Gottlob Frege. Oxford: Blackwell. 1952 .

Gabius, H.-J. (2000). Biological information transfer beyond the genetic code: The Sugar Code. Naturwissenschaften, 87, 108-121.

Gabius, H.-J., André, S., Kaltner, H., \& Siebert, H.-C. (2002). The sugar code: functional lectinomics. Biochimica et Biophysica Acta, 1572, 165-177.

Gamble, M. J., \& Freedman, L. P. (2002). A coactivator code for transcription. TRENDS in Biochemical Sciences, 27(4), 165-167.

Gell-Mann, M. (1994). The Quark and the Jaguar, p. 134. New York: W. H. Freeman.

Gonzalez. (2008). Error detection and correction codes. In M. Barbieri (Ed.), The Codes of Life: The Rules of Macroevolution, pp. 379-394. Dordrecht: Springer.

Hoffmeyer, J. (1996). Signs of meaning in the universe. Bloomington: Indiana University Press.

Hoffmeyer, J. (2008a). Biosemiotics: An examination into the signs of life and the life of signs. Scranton and London: University of Scranton Press.

Hoffmeyer, J. (2008b). A legacy for living systems. Gregory Bateson as precursor to biosemiotics. Dordrecht: Springer.

Khorana, H. G., Büchi, H., Ghosh, H., Gupta, N., et al. (1966). Polynucleotide synthesis and the genetic code. Cold Spring Harbor Symposia on Quantitative Biology, 31, 39-49.

Krampen, M. (1981). Phytosemiotics. Semiotica, 36(3/4), 187-209.

Kull, K. (ed) (2001). Jakob von Uexküll: a paradigm for biology and semiotics. Semiotica, 134 (1/4), Berlin: Mouton de Gruyter.

Markoš, A. (2002). Readers of the book of life: Conceptualizing developmental evolutionary biology. Oxford: Oxford University Press.

Markoš, A. (2004). In the quest for the novelty: Kauffman's biosphere and Lotman's semiosphere. Sign System Studies, 32, 309-327.

Markoš, A., \& Cvrčková, F. (2002). Back to the science of life. Sign System Studies, 30, 127-149.

Markoš, A., Grygar, F., Kleisner, K., \& Neubauer, Z. (2007). Towards a Darwinian biosemiotics. Life as mutual understanding. In M. Barbieri (Ed.), Introduction to Biosemiotics, pp. 235-255. Dordrecht: Springer.

Markoš, A., Grygar, F., Hajnal, L., Kleisner, K., \& Kratochvil, N. Z. (2009). Life as its Own Designer: Darwin's Origin and Western Thought. Dordrecht: Springer.

Mayr, E. (1982). The growth of biological thought. Cambridge: The Belknap Press of Harward University Press.

Newell, A. (1980). Physical symbol systems. Cognitive Science, 4, 135-183.

Newell, A., \& Simon, H. A. (1972). Human problem solving. Englewood Cliffs/NJ: Prentice-Hall.

Nirenberg, M., \& Matthaei, J. H. (1961). The dependence of cell-free protein synthesis in E. coli upon naturally occurring or synthetic polyribonucleotides. Proceedings of the National Academy of Sciences of the United States of America, 47, 1588-1602.

Nirenberg, M., Caskey, T., Marshal, R., Brimacombe, R., et al. (1966). The RNA code and protein synthesis. Cold Spring Harbor Symposia on Quantitative Biology, 31, 11-24. 
Pattee, H. H. (1968). The physical basis of coding and reliability in biological evolution. In C. H. Waddington (Ed.), Toward a Theoretical Biology (1st ed.), pp. 67-93. Edinburgh: Edinburgh University Press.

Pattee, H. H. (1972). Laws and constraints, symbols and languages. In C. H. Waddington (Ed.), Towards a Theoretical Biology, Vol. 4, pp. 248-258. Edinburgh: Edinburgh University Press.

Pattee, H. H. (1973). Hierarchy theory. The challenge of complex systems. New York: George Braziller.

Pattee, H. H. (1980). Clues from molecular symbol systems. Signed and spoken language: Biological constraints on linguistic form. U Bellugi and M. Studdart-Kennedy (Eds.), pp. 261-274. VerlagChemie: Dahlem Konferenzen.

Pattee, H. H. (1995). Evolving self-reference: matter, symbols, and semantic closure. Communication and cognition - artificial intelligence, Vol. 12, Nos. 1-2, pp. 9-27. Special Issue Self-Reference in Biological and Cognitive Systems, Luis Rocha (Ed.).

Pattee, H. H. (2001). The physics of symbols: bridging the epistemic cut. BioSystems, 60, 5-21.

Pattee, H. H. (2007). The necessity of biosemiotics: matter-symbol complementarity. In M. Barbieri (Ed.), Introduction to Biosemiotics, pp. 115-132. Dordrecht: Springer.

Pattee, H. H. (2008). Physical and functional conditions for symbols, codes and languages. Biosemiotics, 1 (2), 147-168.

Peirce, C. S. (1906). The basis of pragmaticism. In C. Hartshorne \& P. Weiss (Eds.), The Collected Papers of Charles Sanders Peirce, Vols I-VI, 1931-1935. Cambridge: Harvard University Press.

Posner, R., Robering, K., \& Sebeok, T. A. (1997). Semiotik/Semiotics: A handbook on the sign-theoretical foundations of nature and culture, Vol. 1, p. 4. Berlin: Walter de Gruyter.

Prodi, G. (1988). Material bases of signification. Semiotica, 69(3/4), 191-241.

Readies, C., \& Takeichi, M. (1996). Cadherine in the developing central nervous system: an adhesive code for segmental and functional subdivisions. Developmental Biology, 180, 413-423.

Rothschild, F. S. (1962). Laws of symbolic mediation in the dynamics of self and personality. Annals of the New York Academy of Sciences, 96, 774-784.

Saussure Ferdinand de. (1916). Cours de linguistique générale. Paris: Payot.

Schrödinger, E. (1944). What is life?. Cambridge: Cambridge University Press.

Sebeok, T. A. (1963). Communication among social bees; porpoises and sonar; man and dolphin. Language, 39, 448-466.

Sebeok, T. A. (1972). Perspectives in zoosemiotics. The Hague: Mouton.

Sebeok, T. A. (2001). Biosemiotics: its roots, proliferation, and prospects. In: K Kull (Ed.), Jakob von Uexküll: A Paradigm for Biology and Semiotics. Semiotica, 134(1/4), 61-78.

Shannon, C. E. (1948). A mathematical theory of communication. Bell Systems Technical Journal, 27, 379-424, 623-656.

Shapiro, L., \& Colman, D. R. (1999). The diversity of Cadherins and implications for a synaptic adhesive code in the CNS. Neuron, 23, 427-430.

Simon, H. A. (1962). The architecture of complexity: hierarchic systems. Proceedings of the American Philosophical Society, 106, 467-482. Reprinted with revisions in The Sciences of the Artificial, 3rd Ed. MIT Press, 1996, pp 183-216.

Simon, H. A. (1973). The organization of complex systems. In H. H. Pattee (Ed.), Hierarchy Theory: The Challenge of Complex Systems. New York: Braziller.

Sonea, S. (1988). The global organism: a new view of bacteria. The Sciences, 28(4), 38-45.

Speyer, J., Lengyel, P., Basilio, C., Wahba, A., Gardner, R., \& Ochoa, S. (1963). Synthetic polinucleotides and the amino acid code. Cold Spring Harbor Symposia on Quantitative Biology, 28, 559-567.

Stepanov, Y. S. (1971). Semiotika. Moscow: Nauka.

Stjernfelt, F. (2007). Diagrammatology. An investigation on the borderlines of phenomenology, ontology, and semiotics. Dordrecth: Springer.

Strahl, B. D., \& Allis, D. (2000). The language of covalent histone modifications. Nature, 403, 41-45.

Trifonov, E. N. (1987). Translation framing code and frame-monitoring mechanism as suggested by the analysis of mRNA and 16s rRNA nucleotide sequence. Journal of Molecular Biology, 194, 643-652.

Trifonov, E. N. (1989). The multiple codes of nucleotide sequences. Bulletin of Mathematical Biology, 51, 417-432.

Trifonov, E. N. (1996). Interfering contexts of regulatory sequence elements. Cabios, 12, 423-429.

Trifonov, E. N. (1999). Elucidating sequence codes: three codes for evolution. Annals of the New York Academy of Sciences, 870, 330-338.

Turner, B. M. (2000). Histone acetylation and an epigenetic code. BioEssay, 22, 836-845.

Turner, B. M. (2002). Cellular memory and the histone code. Cell, 111, 285-291.

Uexküll Jakob von. (1928). Theoretische biologie 2te Auflage. Berlin: Julius Springer. 
von Neumann, J. (1951). General and logical theory of automata. In L. A. Jeffress (Ed.), Cerebral Mechanisms of Behavior, The Hixon Symposium, vol. 5, No. 9, pp. 316-318. New York: Wiley.

von Neumann, J. (1966). The theory of self-reproducing automata. Edited and completed by A. Burks, Urbana, pp. 74-87. IL: University of Illinois Press. Fifth Lecture.

Wigner, E. (1964). Events, laws, and invariance principles. Wigner's Nobel Lecture, Stockholm, 10 Dec. 1963. Reprinted in Science 145, 995-999.

Witzany, G. (1995). From the "logic of the molecular syntax" to molecular pragmatism. Evolution and Cognition, 1(2), 148-168.

Witzany, G. (2000). Life: The communicative structure. A new philosophy of biology. Norderstedt: Libri Books on Demand.

Witzany, G. (2006). The logos of the bios 1. Contributions to the foundation of a three leveled biosemiotics. Helsinki: Umweb. 